\title{
O processo de modernização do Inmetro - relato de uma experiência
}

\section{Apresentação}

O Instituto Nacional de Metrologia, Normalização e Qualidade Industrial (Inmetro) desenvolve, desde o início da década de 90, um vigoroso processo de modernização institucional, visando ao efetivo cumprimento de sua missão, em um contexto de grande dinamismo, e à incorporação dos melhores modelos organizacionais e práticas gerenciais, inclusive os preconizados pelo Plano Diretor de Reforma do Aparelho do Estado.

Apresentar o relato dessa experiência é justamente o que propõe este documento, tendo em vista dois objetivos básicos. Primeiramente, mostrar como certos princípios de organização e de gestão foram efetivamente incorporados ao dia-a-dia do Inmetro. Em segundo lugar, descrever o processo de absorção dos princípios da reforma do Estado no instituto, apesar dos inúmeros obstáculos que tiveram que ser enfrentados e superados. Com isso, espera-se manter acesa a chama da reforma e evidenciar os benefícios decorrentes de sua conclusão e consolidação.

Inicialmente, procurou-se explicitar, de forma sumária, tendo em vista a natureza deste relato, os principais fatores responsáveis pela deflagração do processo de transformação do Inmetro: o processo de redemocratização, a abertura e liberação da economia e a reforma do Estado. Esses são fatores extremamente dinâmicos, que não somente deram partida ao processo, mas influenciaram, e influenciam até hoje, seus desdobramentos.

O ponto seguinte se volta para os modelos e processos de mudança adotados, cujas características mais operacionais foram construídas ao longo do processo. Nesse sentido, serão apresentados, já no seu formato

Ricardo de Oliveira é engenheiro de produção pela UFRJ, exdiretor de operações e tecnologia da

Dataprev e atualmente é coordenador de planejamento do INMETRO, onde conduziu o processo de transformação do órgão em Agência Executiva.

Contato: roliveira@ inmetro.gov.br 
atual, as premissas, os modelos e as estratégias de mudança, bem como os requisitos básicos para sua implantação.

O modelo de gestão do Inmetro - foco básico da mudança será explanado no item "O modelo de gestão do Inmetro". Trata-se, agora, de descrever o Projeto de Organização e Gestão do Inmetro, por meio da explicitação de seus princípios básicos. Da mesma forma que no modelo de mudança, não se partiu de um esquema pronto e acabado, tendo por objetivo apenas a sua implantação. A estratégia adotada, ao contrário, implicava ir detalhando e ajustando o modelo de gestão à medida que sua instalação avançava, com os devidos engajamento e participação dos diferentes parceiros e atores relevantes.

O item "As transformações do Inmetro", por sua vez, tem por finalidade apresentar as principais mudanças institucionais às quais o Inmetro foi submetido, centrando a atenção na sua transformação em agência executiva e na formulação do contrato de gestão. Evidentemente, o Inmetro avançou bastante em outros domínios organizacionais, como, por exemplo, em suas estratégias, em seus métodos e instrumentos de atuação externa, mas o presente relato ficou restrito aos aprimoramentos mais vinculados à Reforma do Estado, em razão dos objetivos deste documento, como explicitado anteriormente.

Ainda, nesse mesmo item, descreve-se o novo sistema de planejamento e acompanhamento orçamentário do Inmetro, cuja inclusão neste relato se deve a duas razões. Primeiramente, por conta das inovações que foram introduzidas no referido sistema, que representam avanços consideráveis em relação às práticas orçamentárias tradicionais da administração pública brasileira. Em segundo lugar, em razão da nitidez como os princípios da reforma do Estado e do modelo de gestão do Inmetro estão presentes e foram fortemente incorporados nas práticas orçamentárias do instituto.

Finalmente, o documento reserva ainda um espaço para apresentar os destaques mais importantes da trajetória de modernização do Inmetro, apresentando, inclusive, algumas de suas conquistas e alguns de seus resultados relevantes.

\section{Fatores impulsionadores da modernização do Inmetro}

O processo de modernização do Inmetro não pode ser plenamente compreendido sem uma visão dos fatores externos que o impulsionaram e lhe forneceram os fundamentos e as configurações básicas.

Na sua origem, a modernização do Inmetro foi deflagrada e modulada pela confluência de três transformações em curso na sociedade brasileira, que se intensificaram a partir de meados da década de 80 , conforme destacado na figura seguinte: 
Figura 1: Transformação em curso na sociedade brasileira?

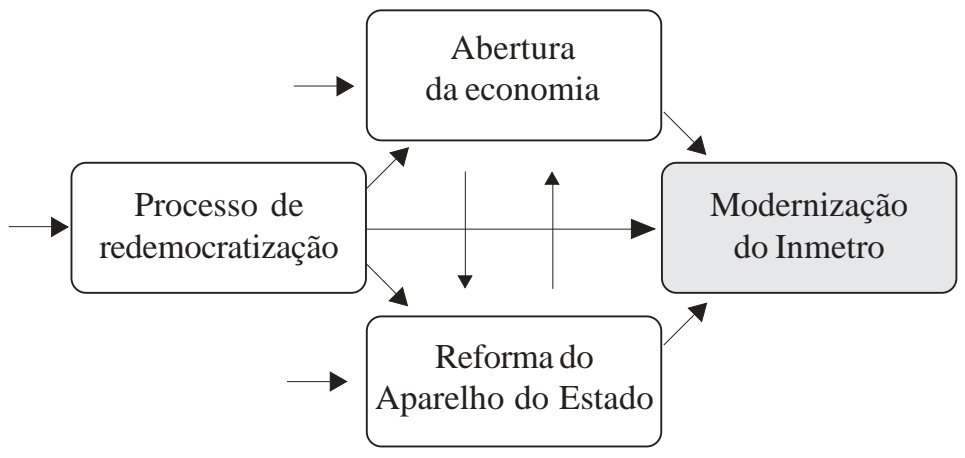

O processo de redemocratização

O processo de redemocratização do país, iniciado na primeira metade da década de 80 e consolidado com a promulgação da Constituição Federal de 1988, "Constituição cidadã", teve intensos reflexos em todos os segmentos da sociedade brasileira. No que se refere aos objetivos deste relato, a redemocratização influenciou fortemente não apenas os fatores influenciadores da modernização do Inmetro (abertura e liberalização da economia e reforma do Estado), como também o próprio instituto, de forma direta.

Cidadania, transparência, defesa e proteção do consumidor-cidadão, servir ao público, igualdade de tratamento e oportunidades, entre outros, foram valores introduzidos ou fortalecidos pelo processo de redemocratização que se refletiram, de forma significativa, nos modelos e processos de modernização do Inmetro.

\section{A abertura e competitividade da economia}

A partir do final dos anos 80, a economia e a sociedade brasileiras foram submetidas a intensos e profundos processos de transformação.

O fenômeno central, pelo menos para os objetivos desta análise, foi a liberalização e a abertura da economia do país, até então caracterizada pelo protecionismo, atrelado a uma política de substituição de importações. O início efetivo do processo ocorreu em 1990, com a instituição da Política Industrial e de Comércio Exterior.

Em continuação ao processo, o governo brasileiro lançou, no final de 1990, o Programa Brasileiro de Qualidade e Produtividade (PBQP). É justamente no bojo do PBQP que ocorre a reformulação do Sistema Nacional de Metrologia, Normalização e Qualidade Industrial (Sinmetro), visando a seu ajustamento à nova realidade da economia e da indústria brasileiras. No novo modelo, os papéis e funções do Inmetro são bastante 
impactados, que se afasta de suas antigas funções operacionais e passa a assumir, mais fortemente, o apoio às decisões e à gestão do sistema, a articulação das instituições integrantes e o credenciamento e a supervisão dos organismos de certificação. O Inmetro deixa igualmente de exercer a função de registro de normas técnicas.

Não bastassem os impactos decorrentes da reformulação do sistema, o Inmetro recebe igualmente outras pressões, que se prolongam por toda a década de 90, em decorrência tanto da maior exposição do setor produtivo brasileiro a uma economia globalizada, quanto dos desdobramentos internos da liberalização econômica em uma sociedade submetida a forte processo de modernização.

Uma visão dos impactos e pressões sobre o Inmetro, resultante do processo de abertura e liberalização da economia, encontra-se resumida no Quadro 1.

\section{Quadro 1: Impactos sobre o Inmetro}

\begin{tabular}{|l|l|}
\hline $\begin{array}{l}\text { Contexto e processos de } \\
\text { liberalização da economia }\end{array}$ & Impactos sobre o Inmetro \\
\hline Reforma do Sinmetro & $\begin{array}{l}\text { Fortalecimento do papel de apoio e } \\
\text { coordenação técnica aos integrantes } \\
\text { do Sinmetro. } \\
\text { Intensificação da função de credencia- } \\
\text { mento e supervisão dos organismos. } \\
\text { Redução ou afastamento do exercício } \\
\text { de funções operacionais do Sinmetro. }\end{array}$ \\
\hline $\begin{array}{l}\text { Abertura da economia, integra- } \\
\text { ção aos blocos regionais e } \\
\text { inserção na globalização }\end{array}$ & $\begin{array}{l}\text { Maior inserção e participação em foros } \\
\text { Ampliação e aceleração da normalização, } \\
\text { regulamentação, avaliação de conformi- } \\
\text { dade e metrologia, relativos a produtos } \\
\text { importados e para exportação. }\end{array}$ \\
\hline $\begin{array}{l}\text { Movimentos internos de } \\
\text { defesa do consumidor e } \\
\text { da concorrência }\end{array}$ & $\begin{array}{l}\text { Integração no Sistema Nacional de } \\
\text { Defesa do Consumidor e nos processos } \\
\text { de educação e proteção do consumidor. } \\
\text { Apoio técnico a entidades públicas e a } \\
\text { agências e órgãos reguladores na defesa } \\
\text { da concorrência. } \\
\text { Ampliação do escopo da regulamentação, } \\
\text { credenciamento, avaliação de conformi- } \\
\text { dade e metrologia. }\end{array}$ \\
\hline
\end{tabular}

\section{A reforma do Estado}

A reforma do Estado brasileiro intensificou-se na década de 90, e teve como eixo básico a revisão dos seus papéis e os modos de intervenção. 
Nessa linha, duas vertentes se tornaram proeminentes: a modernização do aparelho do Estado e o processo de desestatização e desregulamentação da economia.

Na primeira vertente, foram concebidos e implementados novos princípios, modelos de gestão e formas institucionais para a atuação do Estado, visando fortalecer seus papéis básicos: formulação de políticas e prestação de serviços públicos. Nesse sentido, procurou-se imprimir ao aparelho estatal nova dinâmica no seu relacionamento com os órgãos supervisores e maior flexibilidade e autonomia administrativo-financeiras, além de uma gestão mais profissional, com foco no cliente-cidadão e centrada em resultados.

$\mathrm{Na}$ outra vertente, ocorreu um intenso e amplo processo de desestatização e desregulamentação, por meio do qual importantes atividades desenvolvidas no âmbito estatal foram transferidas ou abertas à participação privada. Complementarmente, promoveu-se o fortalecimento do Estado regulador, por meio da instalação de agências especializadas, voltadas, inicialmente, para os serviços públicos concedidos.

Embora de diferentes maneiras, cada vertente da reforma do Estado incidiu sobre o Inmetro, como pode ser visto no quadro seguinte:

\section{Quadro 2: Impactos sobre o Inmetro causados pela reforma} do Estado

\begin{tabular}{|c|c|}
\hline Reforma do Estado & Impactos sobre o Inmetro \\
\hline $\begin{array}{l}\text { Modernização do } \\
\text { aparelho do Estado }\end{array}$ & $\begin{array}{l}\text { Disponibilização de novos valores, modelos e ins- } \\
\text { trumentos organizacionais e de gestão, tais como: } \\
\text { • princípios e valores de modernização. } \\
\text { organizacional; } \\
\text { • novos formatos organizacionais: agências } \\
\text { executivas e OS; } \\
\text { - instrumentos mais modernos de relacionamento } \\
\text { com os órgãos supervisores: contratos de gestão; } \\
\text { - modelos de gestão: administração gerencial; } \\
\text { - concurso público para atrair novos quadros; e } \\
\text { Prómulos e apoios à melhoria da qualidade - } \\
\text { de Qualidade do Governo Federal. }\end{array}$ \\
\hline $\begin{array}{l}\text { Processo de } \\
\text { privatização e } \\
\text { desregulamentação }\end{array}$ & $\begin{array}{l}\text { Fortalecimento da regulamentação, por meio da } \\
\text { instalação de agências reguladoras, pressionando } \\
\text { o Inmetro para: } \\
\text { • ampliação e agilização dos processos de } \\
\text { regulamentação, avaliação de conformidade, } \\
\text { credenciamento e metrologia; e } \\
\text { - intensificação das solicitações de apoio técnico } \\
\text { e parcerias nas agências reguladoras. }\end{array}$ \\
\hline
\end{tabular}




\section{O processo de mudança do Inmetro}

\section{Premissas e modelo de mudança}

A premissa básica adotada pelo Inmetro foi a de que a mudança deveria voltar-se para a produção de resultados para a sociedade, não devendo se limitar apenas a aprimoramentos internos, sem impactos significativos sobre seu ambiente. Melhorias organizacionais e gerenciais, evidentemente necessárias, deveriam, porém, ser vistas como meios e instrumentos para o aumento da efetividade da sua atuação.

A partir dessa premissa básica, foi sendo construído um modelo geral de mudança ou de intervenção, que pressupunha a existência ou a criação das seguintes condições:

a) uma forte pressão social, capaz de legitimar a transformação e reduzir ou conter as maiores resistências;

b) uma liderança forte e consistente, com capacidade de formulação e negociação das linhas básicas do projeto, de articulação dos interesses envolvidos e de condução do processo de mudança;

c) estratégias e requisitos de mudança, que estabelecem as formas e as condições básicas, segundo as quais o processo de transformação do Inmetro deverá ser conduzido;

d) um projeto de organização e gestão da nova instituição, explicitando princípios, processos e instrumentos básicos; e

e) uma forte motivação de atores internos e externos, para seu engajamento nos esforços de implantação e manutenção das mudanças.

Uma visão conjunta e esquemática da premissa e do modelo geral adotados para o processo de reformulação do Inmetro é apresentada na Figura 2.

Figura 2: Processo de reformulação do Inmetro

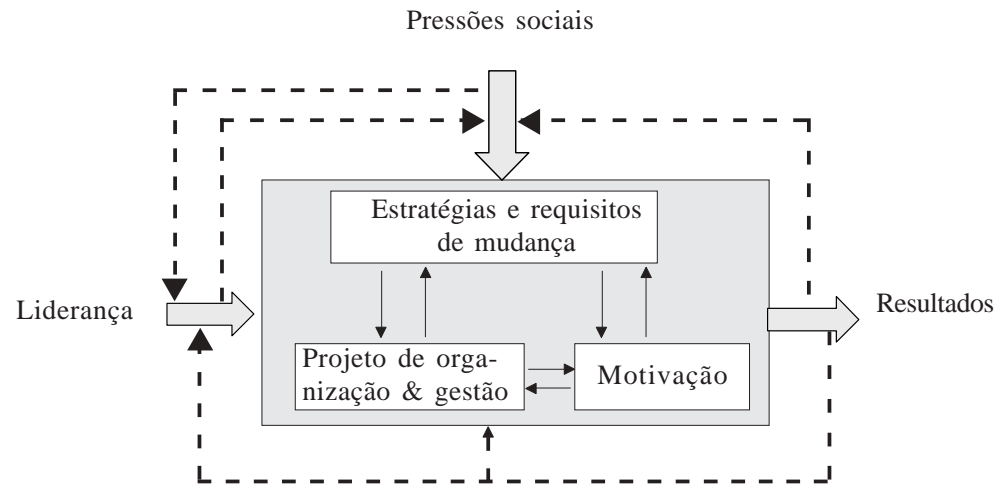


Estratégia da mudança

Um elemento fundamental da estratégia da mudança adotada foi a decisão de centrar a atenção e os esforços iniciais na criação das condições necessárias à viabilização das transformações requeridas, deixando para detalhar o Projeto de Organização e Gestão do Inmetro — foco básico da mudança - à medida que o processo avançasse. Dessa forma, fortalecer a liderança, mobilizar e motivar os principais atores e estimular e reorientar as pressões em beneficio do projeto foram considerados fatoreschave para dar partida e assegurar a efetividade das mudanças.

Nesse quadro, bastava ao Inmetro dispor, inicialmente, de uma concepção geral da configuração de organização e gestão pretendida, suficiente para orientar o processo de mudança e mobilizar os parceiros e decisores mais relevantes. O detalhamento do projeto foi sendo desenvolvido ao longo do processo, simultaneamente com a implantação de seus instrumentos mais estratégicos, à medida que a clareza do modelo e as condições para sua viabilidade foram sendo obtidas. Naturalmente, esse tipo de estratégia exigiu um efetivo mecanismo de monitoramento e avaliação, visando manter o controle do processo pela liderança.

Portanto, a modernização do Inmetro não seguiu um processo linear ou seqüencial, mas assumiu um caráter bastante interativo e circular, no qual cada fator básico não apenas estava sujeito a alterações, mas igualmente atuava sobre os demais, reforçando, modificando ou inibindo seu desenvolvimento.

Nesse contexto, cabe destacar alguns circuitos de interação, que foram muito importantes para as transformações ocorridas no Inmetro.

Saliente-se, inicialmente, a interação representada na figura seguinte:

\section{Figura 3: Circuito interativo}

\section{Pressões sociais $\longrightarrow$ Liderança}

De um lado, a liderança do Inmetro orientou suas ações com base nas pressões sociais que conseguiu reconhecer e valorizar, tais como as demandas por medidas para o avanço na competitividade da indústria nacional e a proteção ao consumidor. Colocam-se aqui, igualmente, as aspirações da sociedade e do governo por uma administração pública moderna, segundo as orientações da reforma do Estado, que o Inmetro procurou internalizar no seu modelo de gestão.

Do outro lado, o comportamento da liderança caracterizou-se por uma postura pró-ativa, no sentido de que o Inmetro induziu as demandas sociais na sua própria direção. $\mathrm{O}$ exemplo mais evidente são os testes de 
qualidade de produtos, cuja veiculação em programa de televisão de grande audiência ("Fantástico") gerou pressões de toda sorte sobre a liderança do Inmetro e, de modo geral, sobre toda a instituição.

Um circuito interativo bem mais complexo é originado a partir dos resultados obtidos, como esquematizado na Figura 4:

Figura 4: Circuito interativo mais complexo

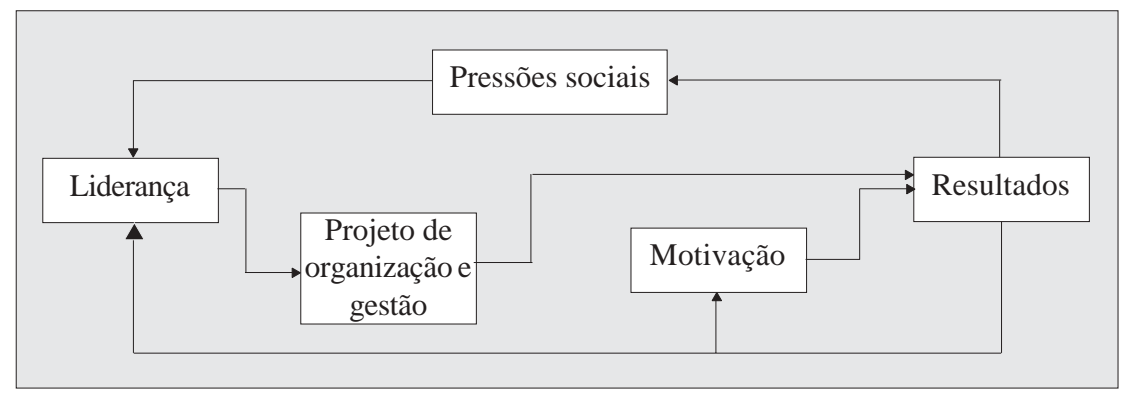

Há aqui uma espécie de ciclo virtuoso da mudança. De fato, à medida que os resultados positivos tornam-se evidentes, seus efeitos começam a ser sentidos, reforçando o prosseguimento das mudanças em andamento.

De um lado, os resultados positivos da ação do Inmetro são percebidos pela sociedade e pelo governo e transformados em novas pressões sociais, levando, inclusive, o instituto a assumir novos papéis e tarefas. Essas novas pressões sociais repercutem na liderança, que não apenas vê suas ações legitimadas, mas pressiona a própria instituição por ajustamentos e maior agilização na organização e gestão, o que incide, por sua vez, na melhoria da qualidade dos resultados produzidos pelo Inmetro. Vale destacar que a atuação da liderança no projeto de organização e gestão voltou-se tanto para a modernização dos instrumentos do Instituto, quanto para a descentralização de suas atividades, ampliando sua rede de parceiros (organismos públicos e privados) e seu raio de ação.

Do outro lado, a constatação dos efeitos positivos dos resultados, percebidos diretamente pela Instituição, serve de feedback à sua liderança sobre o acerto das medidas implantadas, ao mesmo tempo em que incide fortemente sobre o orgulho de seus integrantes, fortalecendo o seu grau de motivação e melhorando o clima organizacional reinante, o que naturalmente não deixa de repercutir favoravelmente sobre os resultados da Instituição.

\section{Requisitos básicos para a mudança}

Além de premissas e modelos, a modernização do Inmetro seguiu uma série de requisitos básicos, que, em consonância com a linha 
estratégica assumida, foram sendo mais conscientemente percebidos, explicitados e modulados ao longo do processo. A seguir serão apresentados os requisitos mais relevantes.

Definição clara de objetivos - A disponibilidade de uma visão clara de objetivos e rumos constitui requisito fundamental para qualquer processo de aperfeiçoamento institucional. Ao longo de todo o processo de modernização, a direção do Inmetro não deixou, em momento algum, de explicitar e disponibilizar a seus colaboradores e parceiros os alvos a atingir e as trajetórias a percorrer, que evidentemente foram sendo aperfeiçoados e ajustados no decorrer dos acontecimentos.

No Plano Estratégico (1993; e 1998-2002), no Plano de Modernização do Inmetro - PMI (1995), e nos sucessivos Contratos de Gestão, os objetivos, as estratégias, os indicadores e as ações do instituto foram sendo sucessivamente explicitados, confirmados e reajustados, sem que fossem deixadas lacunas ao longo da trajetória. Além disso, as sucessivas pesquisas que o Inmetro tem realizado com os clientes e o público em geral servem como importantes balizamentos para confirmação, ajustamentos e correção de rumos.

Capacidade de ganhar adesão — A direção do Inmetro posicionou-se sempre com base na premissa de que o sucesso e a efetiva implantação do processo de modernização dependiam fortemente da credibilidade e confiança de atores externos e de seus funcionários, em relação ao projeto de mudança.

Por sua vez, a construção e a manutenção da credibilidade e da confiança repousavam tanto na participação dos referidos atores e quadros no processo, quanto na transparência e honestidade de propósitos e ações. Duas linhas de ação pareceram, então, fundamentais: a criação de um clima democrático e a divulgação de informações sobre a mudança.

No primeiro caso, a existência de um clima democrático constituía condição essencial para o incentivo à participação, para a incorporação de novas idéias e para a obtenção de objetivos compartilhados. Nesse sentido, em todas as fases de formulação e implantação do projeto, a participação da sociedade e dos quadros do Inmetro foi bastante estimulada, quer por meio do envolvimento direto em seminários e grupos de trabalho, quer por meio da captação de informações e opiniões, por meio de pesquisas e entrevistas.

Em relação à divulgação, adotou-se deliberadamente a postura de que o conhecimento do processo e de sua evolução constituía requisito básico para uma participação efetiva no seu desenvolvimento ("só cobra quem conhece"). Foram, então, utilizadas duas linhas de ação. De um lado, um uso intensivo da mídia junto à comunidade e aos clientes, promovendo-se ampla exposição do Inmetro à sociedade, como uma espécie de prestação de contas. Do outro lado, especialmente para o público interno 
e para o governo, instalou-se um processo de ampla e frequiente divulgação dos progressos da mudança, da melhoria dos resultados e do aprimoramento das operações da instituição, por meio de seminários, jornais internos e relatórios.

Capacidade gerencial para a transformação de objetivos em ações - Para o êxito da mudança, torna-se fundamental agregar uma capacidade empreendedora, visando à tradução dos sonhos em realidade, por meio da transformação efetiva dos objetivos em ações concretas. Essa foi outra preocupação que permeou todo o processo de transformação do Inmetro.

Dois aspectos, porém, precisam ser ressaltados. Primeiro, os objetivos do Inmetro sempre foram formulados tendo em vista a inserção mais efetiva da instituição no esforço de desenvolvimento nacional. Jamais houve a preocupação apenas de definir e buscar metas viáveis e de implantação fácil. A premissa básica do Inmetro sempre foi a melhor contribuição ao país, evidentemente segundo os papéis básicos que lhe cabem.

Segundo, evitou-se assumir uma postura burocrática e rígida de simples cumprimento de modelos e metas originalmente formulados. Em um mundo em permanente e intensa transformação, o comportamento da instituição pública deve ser de permanente agregação de valor às suas atividades. Ao longo do processo, o Inmetro sempre procurou agregar valor às suas atividades, a partir dos ativos e recursos que the foram disponibilizados. A forte entrada do Inmetro no processo de proteção ao consumidor, por meio da realização e divulgação de testes de produtos e serviços, é um exemplo de atuação segundo esses parâmetros.

Disponibilidade e autonomia na aplicação de recursos financeiros - Um outro aspecto básico diz respeito à disponibilidade de recursos financeiros compatíveis com as necessidades do projeto, conjuntamente com a obtenção de flexibilidade e autonomia na sua aplicação. Neste domínio, duas estratégias foram postas em prática.

De um lado, houve um intenso esforço no sentido de aumentar a disponibilidade de recursos financeiros para o Inmetro, inclusive com a forte incrementação do volume dos recursos próprios. Nesse sentido, o Inmetro defendeu reivindicação ao Governo Federal para eliminar contingenciamentos de recursos orçamentários próprios, visando, assim, incentivar os órgãos públicos a expandir suas fontes de receita. No período 19942000, a receita total do Inmetro passou de $\mathrm{R} \$ 53$ para $\mathrm{R} \$ 157$ milhões, com um incremento de quase $200 \%$, sendo que a receita própria representa atualmente cerca de $68 \%$ dos recursos totais.

De outro lado, tornava-se crucial a obtenção de maior autonomia e flexibilidade na aplicação dos recursos públicos, porém dentro de um quadro de responsabilidade fiscal e eficiência financeira. Ficou, então, 
patente a necessidade de o Inmetro buscar modelos institucionais e formas de relacionamento com o governo central mais adequados às exigências do seu projeto de modernização. Engajar-se no movimento de reforma do Estado mostrou ser o caminho mais natural, resultando daí a transformação do Inmetro em agência executiva e a assinatura do contrato de gestão com os órgãos supervisores, como será detalhado mais adiante.

Continuidade na condução do projeto - A manutenção de continuidade administrativa na condução do projeto constituiu outro requisito básico ao seu sucesso. De fato, é justamente a gestão contínua do projeto que possibilita o progressivo aperfeiçoamento dos objetivos, modelos e estratégias, ao longo do processo de implantação do empreendimento.

Não se trata de continuidade em termos da permanência de dirigentes, o que foge totalmente ao controle do instituto. Não significa, porém, que não devam ser buscadas soluções para conferir maior estabilidade à direção das instituições públicas, procurando vincular mais fortemente sua continuidade ao desempenho da organização, para o que o contrato de gestão é um instrumento muito promissor.

Foi a compreensão desse tipo de restrição que levou os dirigentes a centrar a base de sustentação do projeto em seus próprios princípios, modelos e estratégias, e não nas pessoas que, eventualmente, estivessem à frente do Inmetro. Isso requer, por sua vez, a existência de três condições:

1) atualização e divulgação permanentes das bases e dos avanços do projeto;

2) apoio e engajamento efetivo do corpo permanente da organização; e

3) apoio político e aceitação técnica do projeto por parte do governo e parceiros externos.

Articulação, apoio e legitimidade política - A articulação das forças políticas, externas e internas, em torno do projeto de modernização constituiu preocupação constante da direção do Inmetro, durante toda a evolução do processo. Não se trata, necessária ou exclusivamente, de articulação partidária ou com associações de funcionários, mas da construção de uma rede de alianças e parcerias capaz de conferir sustentação e legitimidade políticas ao projeto.

Essa rede envolve os Poderes Executivo, Legislativo e Judiciário, o Ministério Público, os clientes, a rede de credenciados e conveniados, os foros internacionais e regionais, os funcionários da instituição, os formadores de opinião, as organizações não-governamentais e as não menos importantes, comunidades interessadas. Nesse contexto, o ministério supervisor é um ator cujo apoio político não é apenas importante, mas indispensável e decisivo. Sem seu apoio e aprovação, nenhum projeto de modernização seria efetivamente implantado. 


\section{O modelo de gestão do Inmetro}

O processo de modernização do Inmetro requeria, antes de tudo, a formulação do modelo de gestão a ser adotado e que iria constituir o centro do processo de mudança.

A formulação prévia do modelo atendia a três propósitos. Antes de tudo, o modelo sinaliza a qualidade de gestão que se pretende imprimir no Inmetro, em termos de valores, princípios e ferramentas que deverão ser seguidos e aplicados. Em segundo lugar, o modelo serviu para a negociação de apoios e parcerias ao processo de modernização, especialmente no domínio da reforma do Estado. Finalmente, constituiu importante instrumento para o monitoramento do processo de mudança: desvios na implantação de seus parâmetros básicos passaram a ser vistos como sinalizações para ajustamentos nas suas características e/ou nas estratégias de execução das medidas.

Tendo em vista esses marcos gerais, o modelo de gestão do Inmetro foi concebido e implantado com base em cinco princípios, descritos a seguir.

\section{Melhoria da qualidade dos serviços prestados}

A melhoria da qualidade dos serviços prestados indica, na verdade, o redirecionamento explícito do Inmetro para o cliente e para os resultados. Por intermédio desse princípio, a instituição busca reverter uma cultura e uma prática profundamente enraizadas na administração pública, representada pela exclusividade das atenções dos seus gerentes à questão dos meios e dos recursos.

O foco no cliente significa uma preocupação com a efetividade, isto é, com o atendimento às reais necessidades e demandas da sociedade. Internamente, essa mudança representa tanto a introdução, no Inmetro, de uma cultura efetiva de serviço público (servir ao público) em todos seus segmentos, quanto a exigência de um monitoramento permanente do atendimento ao cliente.

Já o foco nos resultados indica a orientação do Inmetro para a eficácia, ou seja, para sua capacidade de estabelecer, buscar e obter resultados, segundo padrões adequados de qualidade e de acordo com as reais demandas da sociedade. Não significa, porém, a desconsideração dos meios e recursos, cuja gestão será objeto de outro princípio, mas apenas sua colocação dentro de uma perspectiva de contribuição para a obtenção dos resultados finais. Em termos internos, essa orientação implica adoção pelo Inmetro da gestão de desempenho, com todas as implicações decorrentes, em termos de descentralização, autonomia, responsabilização e transparência. 


\section{Aprimoramento do controle social}

Esse princípio significa a efetiva abertura do Inmetro à sociedade, atendendo, assim, aos princípios da redemocratização do país e da reforma do Estado. O Instituto tem incentivado e estruturado, de diferentes maneiras, o controle social sobre seus atos.

Primeiramente, a participação direta da sociedade nas decisões relevantes do Inmetro tem sido estimulada, promovida e articulada, quer por meio da sua representação em conselhos do Conselho Nacional de Metrologia, Normalização e Qualidade Industrial (Conmetro), quer por meio do envolvimento de clientes e associações nos grupos e processos de trabalho do próprio instituto.

Em segundo lugar, a transparência do Inmetro tem sido uma das principais preocupações da sua direção, por meio da plena publicidade de seus atos, das atividades realizadas e dos resultados alcançados. Enquadra-se aqui, igualmente, a ampla disponibilização ao público e a entidades de informações relevantes detidas pela organização.

Deve ser destacada, ainda, a forma como os compromissos do Inmetro foram inseridos no contrato de gestão, que passou a ser centrado em indicadores de desempenho associados aos macroprocessos básicos, fugindo-se, assim, à tradicional ênfase em meios e orçamentos. Essa reorientação facilita e estimula o controle social do instituto, tornando o contrato acessível à sociedade, e não apenas aos especialistas em orçamento e administração pública.

O controle social, por sua vez, constitui igualmente um poderoso instrumento de combate ao patrimonialismo e ao clientelismo. No entanto, não é menos relevante salientar que, quando traduzido de forma inadequada, o combate ao patrimonialismo pode constituir um sério entrave ao processo de modernização da administração pública, por meio da intensificação desmedida e distorcida de uma postura essencialmente burocrática de controle. A adequada superação, porém, requer mudanças drásticas nos procedimentos de controle e na cultura gerencial da administração pública brasileira, em suas diversas instâncias e esferas de poder.

É importante destacar que a lógica do novo modelo de gestão do instituto, baseada nos princípios descritos neste item, viabiliza uma gestão voltada, simultaneamente, para resultados e para o exercício de um efetivo controle sobre meios e processos, sem, no entanto, engessar o funcionamento e restringir a evolução da organização.

\section{Obtenção de mais e melhores resultados a um menor custo}

O foco em clientes e resultados, objetivo do primeiro princípio, não significa, de forma alguma, minimizar ou desconsiderar os custos das 
operações e da administração do Inmetro. A eficiência no uso e na aplicação dos recursos continua a constituir um objetivo fundamental.

Dessa forma, não há redução da relevância da gestão dos custos, mas a adoção de uma nova ótica que não restrinja os objetivos e as funções do gestor público a uma dimensão meramente financeira ou orçamentária, embora a referida dimensão não possa ser menosprezada. É imprescindível, pois, que a gestão do Inmetro tenha sido desenvolvida segundo uma perspectiva mais ampla, dotada de um triplo foco, como indicado na figura seguinte:

Figura 5: Triplo foco da gestão no Inmetro

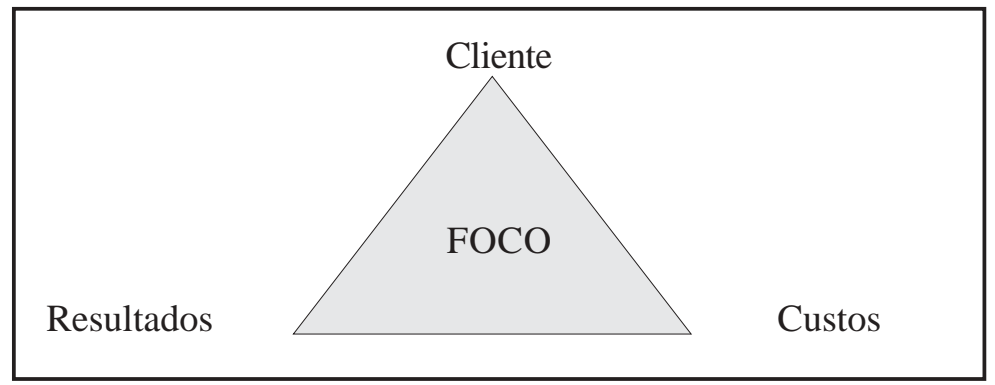

Em suma, o Inmetro posicionou-se no sentido de atender às demandas da sociedade na quantidade requerida e a menores custos. No fundo, o que se pretende é o efetivo exercício de uma gestão baseada no binômio benefício/custo e que implique uma postura empreendedora e voltada para a agregação de valor aos recursos públicos. Nesse contexto, assume importância crucial o conceito de qualidade do gasto, no sentido de permanente preocupação com a maximização dos benefícios, independentemente do volume de recursos previstos ou efetivamente disponíveis. Assim, ao invés de aceitar passivamente uma redução de metas proporcional aos cortes de recursos, a postura centrada na qualidade dos gastos intensificaria os esforços para o incremento da relação benefício/ custo. Isso deveria ser reconhecido pelo governo como estímulo à criatividade e ao espírito empreendedor dos gerentes do setor público, o que, infelizmente, ainda não se concretizou.

\section{Visão abrangente de gestão}

O modelo adotado pelo Inmetro parte de uma visão bastante abrangente do processo e das dimensões de gestão, que pode ser traduzida nos seguintes termos:

a) processo de melhoria contínua; e

b) visão multidisciplinar de gestão. 
No primeiro caso, o processo geral de gestão do Inmetro tem como matriz básica o ciclo PDCA (planejar, fazer, controlar e avaliar), preconizado pelo movimento da Qualidade Total, que pode ser, esquematicamente, representado da seguinte forma:

Figura 6: $O$ ciclo PDCA de gestão

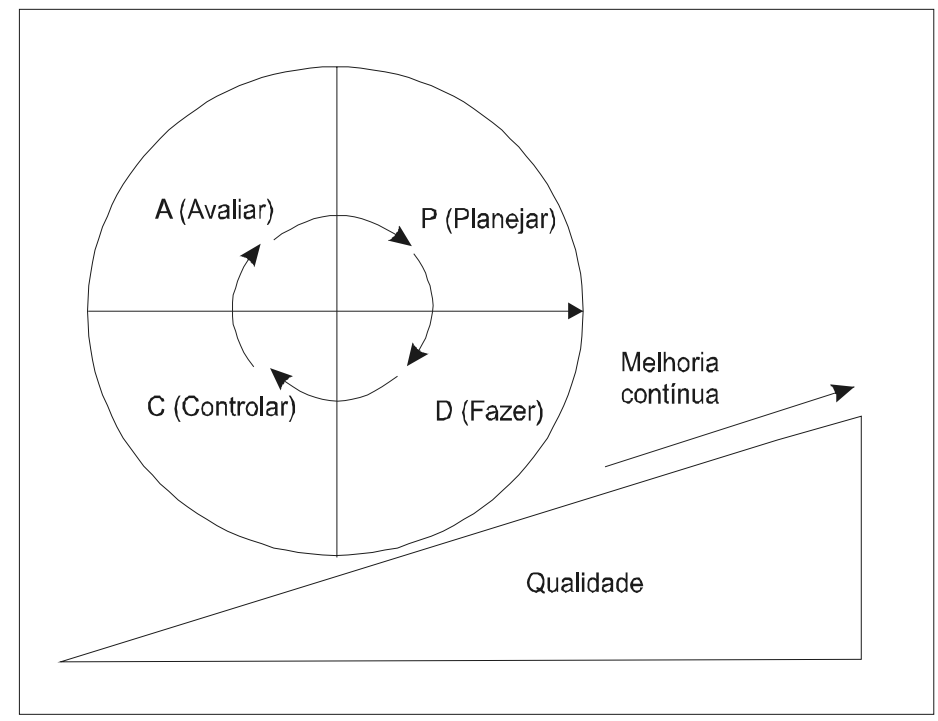

No segundo caso, o modelo de gestão pretende atingir um largo espectro das decisões e ações organizacionais, centrando-se nas três dimensões indicadas na Figura 7:

\section{Figura 7: Dimensões da gestão}

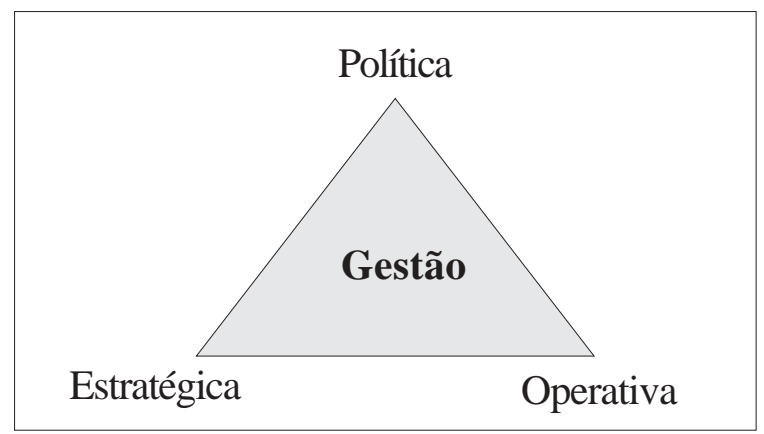

A gestão política visa à construção do apoio e da legitimidade para as estratégias e ações do Inmetro. Já a gestão estratégica trata de conferir visão prospectiva à instituição, antecipando cenários e oportunidades futuras e definindo estratégias de posicionamento e de ação. 
Finalmente, a gestão operativa tem por finalidade a transformação das estratégias em ações concretas, articulando sua execução e monitorando suas condições de viabilidade e seus efeitos sobre a comunidade.

Em suma, a complexidade e a dimensão dos desafios que o Inmetro enfrenta não mais lhe permitem a adoção de modelos gerenciais baseados em perspectiva simplista e linear de suas funções e processos.

\section{Valorização do servidor público}

Esse princípio constitui, na verdade, a âncora de todo o processo de modernização da instituição. De fato, a reformulação do Inmetro repousa fundamentalmente na criação e manutenção de condições objetivas de valorização, desenvolvimento e reconhecimento pessoal e profissional dos seus quadros, que, em última instância, serão os responsáveis pela mudança e operação do Inmetro dentro dos novos parâmetros.

\section{Duas observações assumem aqui importância especial}

De um lado, valorizar o servidor não pode implicar apenas seu desenvolvimento técnico e profissional, embora esta condição seja fundamental. É preciso ir mais além, no sentido de estimular sua capacidade empreendedora e criativa, tornando-o apto para promover a agregação de valor às atividades, fortalecendo, ao mesmo tempo, o espírito público de sua missão e o comportamento ético nas suas ações. Trata-se, em suma, de promover o resgate da auto-estima do funcionário do Inmetro e de fortalecer o profissionalismo nas suas relações de trabalho.

De outro lado, a valorização do servidor não pode significar também a adoção de uma atitude paternalista, no sentido de imprimir um tratamento indiferenciado ao pessoal do Inmetro, sob o argumento de evitar discriminações. Pelo contrário, valorizar o servidor deve significar a aceitação da existência de diferenças e a adoção de postura conseqüente, que "trate diferentemente os desiguais", reconhecendo e premiando os desempenhos superiores.

Todavia, a adoção dessa última postura ainda não pôde ser traduzida em medidas concretas no Inmetro, embora não apenas esteja na sua pauta há bastante tempo, como também seja considerada um princípio fundamental à efetiva implantação do seu processo de modernização. As medidas mais conseqüentes e impactantes nesse domínio, porém, dependem de mudança na legislação pertinente e de avanços na reforma do Estado, ainda não concretizados. 


\section{As transformações do Inmetro}

\section{Antecedentes}

$\mathrm{Na}$ realidade, as transformações organizacionais e gerenciais recentes, pelas quais vem passando o Inmetro, tiveram início logo após as mudanças institucionais ocorridas no Sinmetro, no começo da década de 90. Nesse início, muitos ajustamentos e reformas tiveram que ser, imediata e incrementalmente, implementados no Inmetro, como não podia deixar de ser.

À medida que as demandas e a atuação externas do Inmetro se intensificavam, ajustamentos organizacionais mais profundos tornaram-se inevitáveis, principalmente nas áreas e macroprocessos finalísticos. Nesse quadro, a primeira tentativa ordenada de mudança foi formalizada por meio do PMI 1995-1997, contendo 29 projetos modernizadores, a maioria dos quais voltada para a reestruturação e o fortalecimentos dos macroprocessos.

Embora o plano contivesse uma série de projetos de natureza organizacional e gerencial, todos de elevada relevância para o Inmetro, ainda se estava diante de uma visão desconectada. Não estava previsto qualquer projeto voltado para uma revisão geral da sua configuração organizacional ou gerencial, embora existissem algumas iniciativas bastante reestruturadoras, como o Planejamento Estratégico do Sinmetro ou o Contrato de Gestão, já previsto em 1995.

Como conseqüência do PMI, o Inmetro obteve sucesso considerável no redirecionamento do seu foco de atuação, tendo como suporte ampla e profunda visão dos cenários e desafios mundiais e nacionais. Da mesma forma, progressos relevantes foram obtidos em relação não apenas aos macroprocessos e funções finalísticas (metrologia, credenciamento, avaliação de conformidade), como também aos instrumentos e mecanismos de administração interna.

No entanto, esses importantes avanços nos processos estratégicos e de modernização das áreas-fim do Inmetro não serão relatados neste documento, que se deterá exclusivamente nas transformações institucionais e gerenciais mais vinculadas à reforma do Estado, como já explicitado.

\section{A transformação do Inmetro em agência executiva e o contrato de gestão}

\section{A agência executiva}

Como foi visto, diante das pressões e demandas decorrentes da abertura da economia, da conscientização do consumidor e da reformulação do Sinmetro, o Inmetro promoveu forte redirecionamento de seu foco de atuação e aprimoramento dos macroprocessos finalísticos. 
No entanto, à medida que o instituto avançava na sua estratégia de inserção no novo contexto, dois fatores ficavam cada vez mais evidentes:

a) os aprimoramentos organizacionais efetuados já não mais se mostravam eficazes ou suficientes para atender às demandas e os desafios apresentados ao instituto, aos modelos e práticas significativamente diferentes dos até então implantados; e

b) os novos modelos e práticas requeridos exigiam transformações ou condições que extrapolavam as competências institucionais do Inmetro e, até mesmo, o quadro legal ou formal vigente na administração pública brasileira.

É justamente percebendo esse impasse que a instituição se aproxima e se insere fortemente no movimento de reforma do Estado, comandado, então, pelo Ministério da Administração e Reforma do Estado (Mare). De fato, ficou logo evidente para o Inmetro a existência de uma perfeita sintonia entre os princípios e modelos organizacionais requeridos pela instituição e os preconizados pelo Plano Diretor de Reforma do Aparelho do Estado. Dessa forma, inserir-se nesse movimento pareceu o caminho natural e lógico para o Inmetro conseguir as condições requeridas, para promover as mudanças visualizadas por sua direção.

Tendo em vista o conjunto de instrumentos disponibilizados pelo Plano Diretor, transformar o Inmetro em agência executiva constituía a solução mais adequada para conferir-lhe as capacidades e competências exigidas pelo novo contexto, por três razões básicas:

a) a agência executiva é a solução institucional preconizada pelo Plano Diretor para entidades que exercem funções exclusivas de Estado, condição na qual o Inmetro se enquadra perfeitamente;

b) segundo o Plano Diretor, as agências executivas devem desfrutar de elevada autonomia e flexibilidade administrativa, operacional e financeira, condição julgada indispensável pela direção do Inmetro para cumprir adequadamente as exigências que lhe eram apresentadas; e

c) o modelo de gestão da agência executiva, ainda segundo o Plano Diretor, deve adotar os princípios e parâmetros da "administração gerencial", o que coincidia perfeitamente com os requisitos de gestão e funcionamento ideais para o novo Inmetro.

Todavia, entre outras exigências, a transformação do Inmetro em agência executiva requeria a formulação e aprovação de um contrato de gestão com o ministério supervisor, o então Ministério da Indústria, do Comércio e do Turismo.

\section{$O$ contrato de gestão}

O contrato de gestão desempenha dois papéis básicos distintos, embora fortemente interligados. Formalmente, como já se destacou, 
constitui pré-requisito indispensável à qualificação de uma autarquia como agência executiva. Do ponto de vista gerencial, o Contrato exerce a função de disciplinamento das relações entre a agência e seus órgãos supervisores, ao mesmo tempo em que baliza e restringe as práticas de gestão interna.

Neste último sentido, o contrato é uma ferramenta que complementa e operacionaliza a autonomia e as flexibilidades administrativas e financeiras conferidas às agências executivas. Além disso, é por meio do contrato que o instituto explicita e põe em prática grande parte de sua filosofia de gestão, indicando quais são os focos básicos de sua atuação e preocupação.

Na sua essência, o contrato de gestão do Inmetro baseia-se nos dois seguintes princípios:

a) focalização em resultados; e

b) integração entre fins e meio.

Focalizar o contrato de gestão em resultados já retrata em si um elemento básico do modelo de gestão do Inmetro. Além disso, a forma de desdobramento dos resultados no contrato constituiu igualmente oportunidade para o instituto complementar a explicitação de seus princípios de atuação.

Neste sentido, o Inmetro, por meio do contrato de gestão, decompôs seus resultados em dois conjuntos básicos:

a) resultados globais - que constituem os indicadores corporativos, expressos em termos de imagem externa, confiabilidade junto à população, aumento de receita própria, entre outros; e

b) resultados de atendimento — referentes à prestação de serviços associados a cada um dos macroprocessos finalísticos do Inmetro (credenciamento; informação tecnológica; avaliação de conformidade; controle metrológico; e padronização e disseminação de unidades de medida).

Para cada macroprocesso, foram então formulados indicadores, segundo três perspectivas distintas:

- efetividade - voltada para medir o grau de atendimento do macroprocesso à função social do Inmetro, tomando como foco a sociedade;

- eficácia — tendo em vista a mensuração da qualidade da prestação dos serviços vinculados aos macroprocessos; e

- eficiência - objetivando a otimização dos recursos do Inmetro e de cada um dos seus macroprocessos.

Além desse conjunto de indicadores, o contrato de gestão do Inmetro explicita dois tipos de compromissos:

- obrigações do Inmetro - metas e indicadores de desempenho que o instituto se compromete a alcançar, com base na capacidade instalada; 
e aprimoramentos organizacionais, gerenciais e de capacitação profissional, visando aumentar seus padrões de efetividade, eficácia e eficiência, em consonância com os desafios a serem enfrentados; preservação e crescimento do patrimônio público; e

- compromissos dos ministérios - referentes à disponibilização de recursos orçamentários e financeiros; promoção de medidas e de condições para ampliação da autonomia e flexibilidade administrativa e financeira do Inmetro, compatíveis com as obrigações assumidas pelo instituto.

Dessa forma, o contrato de gestão constituiu a via por meio da qual o Inmetro transformar-se-ia em organização voltada para resultados e dotada das condições básicas para uma gestão equilibrada, segundo os indicadores de efetividade, eficácia e eficiência. Não significa necessariamente que todas as dimensões devam desfrutar do mesmo peso, mas, sim, que todas elas deverão ser explicitamente consideradas, por ocasião da formulação das políticas e planos para o instituto. A natureza do órgão público do Inmetro e a conseqüente ênfase na sua função social tornaram a efetividade a dimensão de maior relevância na gestão do instituto, seguindo-se, em escala de prioridade, os indicadores de eficácia e eficiência, nesta ordem.

\section{O processo de transformação}

Para concretizar a transformação pretendida, o Inmetro desenvolveu um processo de negociação com o governo, iniciado em janeiro de 1996, por meio da assinatura de um protocolo de intenções, que se estendeu até julho de 1998, com a publicação do decreto de qualificação do instituto em agência executiva. Com isso, o Inmetro constituía-se na primeira entidade pública brasileira a obter a qualificação de agência executiva.

Esse pioneirismo, porém, teve um preço bastante elevado. No decorrer do processo, surgiram enormes dificuldades à efetivação da transformação em agência e à aprovação do contrato requerido, principalmente em razão da falta de referenciais e experiências prévias, o que, inclusive, explica o longo tempo consumido no processo.

Todavia, embora a maioria das dificuldades tenha decorrido do ineditismo da solução, muitos obstáculos tiveram origem na resistência ao modelo institucional e ao contrato, cujos requisitos contrariavam os interesses, as lógicas e os poderes já consolidados. Nesse sentido, a crise financeira do Estado constituiu fator adicional de resistência, à medida que exigia da equipe econômica postura mais centralizadora em relação ao controle dos gastos, prejudicando fortemente a devida concessão de autonomia e flexibilidade ao Inmetro, condições básicas para a sua efetiva transformação em agência executiva e para a operacionalização do respectivo contrato de gestão. 
Não houve a compreensão de que o processo de modernização da administração pública não significa, necessariamente, o enfraquecimento do controle dos gastos. O que se pretendia, em última instância, era a introdução de novos modelos institucionais e formas de gestão, que não apenas fossem mais eficazes e transparentes em relação aos gastos, mas que igualmente permitissem melhores condições para o controle social. É justamente o que acabou acontecendo no interior do Inmetro, como será visto mais adiante.

Na realidade, o foco básico das discussões e dificuldades do processo centrou-se na formulação e aprovação do contrato de gestão. Além das resistências já mencionadas, houve dificuldades na obtenção de consenso tanto a respeito de que flexibilidades conceder ao Inmetro, quanto aos focos e indicadores de medição. Como não havia precedente, o modelo geral de contrato de gestão para as agências executivas terminou sendo construído e moldado no processo de transformação do Inmetro.

Além de tudo, a preocupação em se dispor de instrumento realmente efetivo constituiu fator adicional de complicação para o processo. De fato, esse tipo de preocupação levou à inclusão, entre os signatários do contrato, além do ministério supervisor (o então Ministério da Indústria, do Comércio e do Turismo), como era natural, dos ministérios provedores de recursos (Ministérios da Administração e Reforma do Estado, da Fazenda e do Planejamento), o que ampliou bastante o espaço e a complexidade das negociações.

De qualquer forma, o processo de transformação institucional do Inmetro e a aprovação do correspondente contrato de gestão permitiram a obtenção de algumas flexibilidades administrativas e ajudaram o instituto a redirecionar o foco das suas relações com os órgãos supervisores. Mas é inegável que a implantação do processo foi bastante lenta e os ganhos ficaram muito aquém das pretensões iniciais.

Não se pode esquecer, porém, que esse processo constituiu um marco na modernização da administração pública, consolidou princípios e modelos e abriu caminho para a viabilização de novas transformações, tendo agora como referencial essa experiência. O Inmetro entrou nesse processo muito consciente de que, dificilmente, o modelo ideal seria atingido logo na primeira rodada. Seu engajamento visou igualmente contribuir para a manutenção, o fortalecimento e a consolidação do processo de reforma do Estado.

Finalmente, cumpre destacar que a longa discussão que se travou, interna e externamente, durante o processo de modernização, ajudou o Inmetro a absorver e consolidar valores e comportamentos inerentes à "administração gerencial". O exemplo mais patente dessa incorporação de valores e posturas é o novo sistema de planejamento e acompanhamento orçamentário cujas principais características são descritas no próximo item. 
O novo sistema de planejamento e acompanhamento orçamentário

\section{Caracterização da situação inicial}

Até o ano de 1997, o processo orçamentário do Inmetro seguia, em suas linhas básicas, o modelo geral, que ainda prevalece na administração pública brasileira. Nesse contexto, a execução do processo era praticamente restrita à unidade e às equipes orçamentárias, com o orçamento constituindo mera peça formal e abstrata para os demais integrantes da instituição.

Evidentemente, os gerentes e técnicos programavam suas atividades, mas não eram estabelecidas vinculações diretas entre as programações e os recursos orçamentários requeridos, quer na fase de planejamento, quer na etapa de execução. Dessa forma, embora pudessem possuir uma visão razoavelmente precisa do que lhes cabia fazer, técnicos e gerentes não dispunham de informações sobre os correspondentes recursos orçamentários.

$\mathrm{Na}$ realidade, nem os gerentes, nem as equipes de orçamento dispunham de informações precisas a respeito dos recursos destinados às atividades do Inmetro, mesmo as mais estratégicas. Os primeiros, por não participarem da programação orçamentária, e os últimos, por alocarem os recursos segundo os itens de despesas (pessoal, material, serviços de terceiros etc.) das unidades, e não de acordo com suas atividades ou processos, por conveniência dos seus próprios controles burocráticos.

Nesse contexto, como ocorre praticamente em toda a administração pública brasileira, o Inmetro adotava, como modelo básico, a gestão da dotação orçamentária. Em conseqüência, os gerentes da instituição não eram estimulados a incorporar, em seus comportamentos, a prática efetiva de gerenciamento de recursos nem incentivados a se sentirem responsáveis pelos custos e receitas de suas unidades. Nesse sentido, limitavam-se a solicitar os insumos necessários às suas atividades, que, no máximo, tinham sido vagamente previstos nas fases de programação, deixando que as unidades corporativas resolvessem a questão, por meio de jogo burocrático de forte influência pessoal, cuja característica principal era a completa falta de transparência para os gerentes, para a instituição e, conseqüientemente, para a sociedade.

\section{O novo sistema}

A decisão da direção do Inmetro para a radical reformulação do seu sistema de planejamento e acompanhamento orçamentário baseou-se essencialmente em duas razões.

Primeiro, tratava-se de superar as deficiências e insuficiências que o processo orçamentário do Inmetro apresentava, como caracterizado 
anteriormente, que tendiam a se agravar ainda mais. De fato, a situação vigente, que já era insatisfatória em si, tornava-se cada vez mais insustentável, à medida que o Inmetro avançava no planejamento estratégico e se incorporava ao movimento da reforma do Estado, absorvendo seus princípios e conceitos, principalmente os relacionados à administração gerencial.

Segundo, partiu-se do reconhecimento de que o sistema de planejamento e acompanhamento orçamentário é um dos instrumentos mais influentes e de maior penetração na prática e na cultura gerencial de qualquer organização. Portanto, o referido sistema desfrutava das condições ideais para a efetiva implantação de inúmeros princípios preconizados no modelo de gestão do Inmetro. Dessa forma, orientações e diretrizes fundamentais ao modelo de gestão, tais como, descentralização, transparência, responsabilidade fiscal, predominância dos fins sobre os meios, entre outras, encontram-se fortemente presentes no novo sistema, como se verá nos itens seguintes.

\section{Os objetivos e diretrizes para o novo sistema}

Em última instância, o novo sistema visa dotar o Inmetro de ferramenta capaz de formular propostas orçamentárias e acompanhar sua execução, de forma participativa, descentralizada e controlada, permitindo a introdução de uma gerência de recursos efetiva e transparente, exercida em todos os níveis hierárquicos e solidamente vinculada ao planejamento do instituto e ao Sistema de Planejamento e Orçamento do Governo Federal.

A concretização desse objetivo requereu sua tradução em um conjunto de diretrizes, descritas a seguir:

a) introduzir uma gestão efetiva de recursos, receitas e despesas, envolvendo todos os níveis hierárquicos tanto nos projetos, quanto nos processos ou atividades;

b) induzir uma prática gerencial, segundo os princípios da responsabilidade fiscal, vinculando à realização de despesas a existência prévia de receita que as financie;

c) promover a integração entre o planejamento estratégico e operacional e o processo orçamentário do Inmetro, transformando, efetivamente, o orçamento na dimensão financeira dos planos;

d) permitir a consistência do processo orçamentário do Inmetro e sua interatividade com o Sistema de Administração Financeira Federal (Siafi);

e) implementar uma gestão orçamentária descentralizada, permitindo que cada gerente da instituição formule sua própria proposta e opere diretamente a execução orçamentária de seus projetos e de suas atividades, porém submetido às leis e regras que regem a administração orçamentária federal; 
f) viabilizar uma prática orçamentária ágil, transparente e confiável, disponibilizando diariamente, a todos os níveis gerenciais, dados atualizados e oficiais a respeito da execução orçamentária das ações de todo o Inmetro; e

g) informatizar e colocar em rede todo o processo orçamentário do Inmetro, conferindo-lhe elevadas agilidade e interatividade e permitindo a eliminação de procedimentos manuais e de formulários em todas as fases de elaboração e acompanhamento do orçamento.

\section{A estrutura do sistema}

Estruturalmente, o novo sistema foi organizado nos seguintes módulos:

- Módulo de proposta da receita e despesa - Vincula a proposta de receita e despesa do Inmetro às metas do seu plano estratégico, ligando, assim, o processo orçamentário às perspectivas de futuro da instituição. Torna possível a eliminação de formulários, a redução da burocracia e da centralização, ampliando, consequientemente, o grau de participação dos gerentes e técnicos.

- Manual de entrada de dados - Contém informações sobre padrões, especificações, preços e momentos ideais de aquisição de insumos, permitindo que os gerentes possam formular diretamente as propostas orçamentárias para suas unidades. Permite a racionalização e a articulação das compras do instituto, bem como a explicitação das estratégias e regras das áreas meio, por meio de orientações aos gerentes, para suas solicitações de aquisição. A partir dessas entradas, elabora-se um plano anual de compras para os diferentes itens, que permite aferir a consistência entre as solicitações efetivas dos gerentes e as orientações prévias fornecidas pelas áreas meio.

- Módulo de execução orçamentária — viabiliza o relacionamento entre o Siafi e o Siplan do Inmetro e possibilita a extração de dados do Siafi. Permite aos gerentes executar, sem necessidade de autorização prévia, os recursos liberados, disponibilizando informações sobre os saldos resultantes. Enfim, permite que a gestão e o monitoramento orçamentários sejam exercidos efetivamente pelos próprios gerentes, respeitadas naturalmente as regras gerais da administração orçamentária do governo;

- Módulo saldo corrente - Permite que, imediatamente após uma decisão gerencial de efetuar determinado gasto, o bloqueio dos recursos correspondentes seja imediatamente efetuado, enquanto o processo ainda segue seu trâmite formal. Dessa forma, o gerente recebe informações sobre os gastos já iniciados, mas ainda não processadas pelo Siafi; e 
- Módulo pré-proposta orçamentária - Permite que a formulação da pré-proposta orçamentária do Inmetro, a ser negociada com o Governo Federal, tenha como base os grandes balizamentos do planejamento do instituto. Possibilita, assim, a adoção de sistemática mais consistente para a negociação dos recursos orçamentários globais, fugindo do procedimento tradicional, caracterizado pela definição dos montantes do orçamento futuro, com base exclusivamente nos valores do orçamento corrente.

\section{Características básicas da operação do sistema}

A implantação do Sistema de Planejamento e Acompanhamento Orçamentário do Inmetro, segundo os parâmetros descritos anteriormente, resultou em uma gestão orçamentária profundamente distinta das práticas até então vigentes, como o demonstra a descrição seguinte, que aborda alguns dos pontos básicos do processo instalado:

a) subordinação clara dos meios aos fins, pela precedência do planejamento operacional (formulação de metas e indicação de serviços, materiais, equipamentos, instalações, etc. requeridas) sobre a programação orçamentária, com o orçamento passando a constituir, efetivamente, a tradução financeira das decisões programadas;

b) envolvimento real e direto dos gerentes e técnicos de todas as áreas no processo de planejamento e acompanhamento orçamentário, por meio de sua participação nas seguintes fases básicas:

- programação operacional e financeira de seus processos e projetos, quantificando, física e financeiramente, os insumos necessários;

- execução orçamentária, por meio do manejo e apropriação, sem necessidade de autorização prévia dos recursos liberados e da obtenção direta de informações sobre saldos orçamentários e sobre as despesas realizadas, mas ainda não processadas pelo Siafi;

c) participação efetiva das áreas e funções corporativas (compra, treinamento, informática etc.) no processo orçamentário, por meio do fornecimento de orientações, para o orçamento, de aquisição dos diferentes setores do Inmetro, da discussão conjunta com as áreas sobre suas demandas de insumos e, finalmente, do gerenciamento de planos anuais de compra;

d) consequiente adoção por parte de cada área meio de novo e mais ativo papel no processo de gestão orçamentária do Inmetro, com o estabelecimento de efetivo diálogo com as unidades finalísticas e com os demais setores funcionais;

e) adoção de medidas concretas para o estreitamento do diálogo entre as áreas - que terminou extrapolando inclusive os limites da gestão orçamentária -, principalmente por meio da criação e implantação das seguintes instâncias organizacionais: 
- grupos de trabalho especializados, compostos de representantes das áreas meio e finalísticas envolvidas, tendo em vista aprimorar suas formas de atuação e de relacionamento; e

- comitê de gestores dos planos anuais, composto por coordenadores dos grupos de trabalho mencionados, visando à troca de experiência e à discussão das boas práticas de gestão, inclusive orçamentária;

f) criação, no corpo gerencial, técnico e administrativo, de compromisso efetivo com o gerenciamento de recursos, devido à ampla difusão na instituição da imprescindível vinculação e dependência entre o gasto e sua fonte de financiamento, introduzindo, assim, no dia-a-dia do Inmetro, a prática da responsabilidade fiscal; e

g) implantação efetiva de uma gestão de caixa no Inmetro, por meio do estabelecimento de fluxo de caixa planejado de receitas e despesas, geral e setorial, e de seu acompanhamento mensal.

\section{Considerações finais}

A modernização da administração pública é um imperativo do mundo atual. Não se pode mais admitir uma administração ineficiente e ineficaz em recursos públicos, principalmente em sociedades altamente carentes de serviços públicos, em quantidade e qualidade. É fundamental incentivar gerentes e técnicos para agregarem valor às suas atividades, buscando o cumprimento dos objetivos sociais por meio da prestação de serviços com qualidade e ao menor custo possível.

A trajetória do Inmetro nos últimos dez anos, conforme foi relatado anteriormente, mostrou que isso é possível, mesmo em um quadro de fortes restrições. A existência de lideranças firmes e decididas, desde que devidamente orientadas, pode mobilizar a organização e seus parceiros externos relevantes, no sentido da implantação de gestão inovadora e centrada em princípios e modelos consistentes com os desafios e papéis sociais da organização.

Para essa caminhada, a adesão aos princípios e modelos preconizados pela reforma do Estado e a parceria com a equipe por ela responsável constituíram fatores fundamentais e decisivos. A transformação pioneira do instituto em agência executiva e a formulação do contrato de gestão são exemplos fundamentais dessa parceria, mas não atestam devidamente toda a riqueza do processo de modernização.

Outras melhorias não menos importantes foram a instalação efetiva do planejamento estratégico, a implantação e operação de moderno sistema de planejamento e acompanhamento orçamentário, os aprimoramentos nos macroprocessos finalísticos, a introdução de gestão centrada em 
hierarquia consistente de indicadores e o desenvolvimento e a implantação de pesquisa de satisfação do cliente/usuário. Esses avanços levaram, inclusive, o Inmetro à conquista, por reconhecimento, do Prêmio de Qualidade do Governo Federal.

No entanto, as conquistas obtidas pelo Inmetro não se limitam aos aspectos institucionais e organizacionais, mas se refletem, fortemente, em sua imagem e em seu desempenho, consistentemente com a premissa básica de foco nos resultados, que orientou todo o processo de transformação.

Apenas a título de exemplificação, destacam-se, em seguida, alguns dos marcos atingidos:

1) o Inmetro é atualmente conhecido por $62 \%$ da população brasileira;

2) dentre os que o conhecem, $86 \%$ confiam nele e $85 \%$ utilizam as informações do Inmetro nas suas decisões de compra;

3) a satisfação do usuário em relação ao Inmetro, medida pelo Serviço de Atendimento ao Cidadão e pelo Serviço Via Internet, atingiu, em 2001, índices de $88,1 \%$ e 79,3\%, respectivamente;

4) a satisfação do usuário com a certificação compulsória, com a verificação dos instrumentos de medir e a confiabilidade dos exportadores com o sistema metrológico atingiram, no ano de 2001, índices de 95,5\%, $95,8 \%$ e $93,5 \%$, respectivamente;

5) o Inmetro criou uma forte marca, e com elevada credibilidade junto à população, ocupando um espaço na mídia equivalente a $100 \mathrm{mi}$ lhões de reais, apenas nos três primeiros anos, totalmente financiados pelos parceiros, ou seja, não se usaram de recursos públicos em mídia;

6) o número de instrumentos verificados, em todo o país, passou de 3 milhões, em 1994, para 11 milhões, em 2001; e

7) a receita própria do Inmetro aumentou de $\mathrm{R} \$ 40$ milhões, em 1994, para R\$ 121 milhões, em 2001.

Apesar da significativa evolução do Inmetro, sob vários prismas, não se pode deixar de constatar que, em termos institucionais, os resultados ficaram, pelo menos até o momento, aquém da expectativa inicial. As flexibilidades e autonomias administrativas e financeiras, preconizadas pela reforma, não foram alcançadas. Portanto, embora o Inmetro já esteja qualificado como agência executiva, seu processo de transformação não pode ser dado por concluído. As negociações com o governo precisam avançar, até que se obtenha um modelo de gestão condizente com os desafios enfrentados, corrigindo-se as falhas e insuficiências ainda existentes.

Essa evolução, porém, depende fortemente dos avanços do processo de reforma do Estado, principalmente no que tange às formas de controle e às flexibilidades e autonomias efetivamente conferidas às agências executivas. Mantido o estágio atual da reforma, dificilmente o 
Inmetro, ou qualquer outra instituição pública federal, poderá avançar mais no seu processo de modernização, independente de seu potencial de mudança e das necessidades da sociedade brasileira. Corre-se até mesmo o risco de retrocesso nas conquistas já alcançadas, caso as frustrações e as desmotivações com a falta de avanço se acumulem além dos limites. 


\section{Resumo \\ Resumen \\ Abstract}

\section{O processo de modernização do Inmetro — relato de uma experiência Ricardo de Oliveira}

A intenção do autor é mostrar que é possível avançar na implantação, em uma instituição pública brasileira, de modernos princípios de gestão, mesmo em um quadro de fortes restrições. Tem sido justamente esta a trajetória do Inmetro, que, desde o início da década de 90, desenvolve um vigoroso processo de mudança. A partir de um certo momento, o Inmetro aproximou-se do movimento de Reforma do Aparelho do Estado, conduzido pelo Ministério da Administração Federal e Reforma do Estado (MARE), cujas premissas mantinham uma forte sintonia com os princípios adotados na modernização do Instituto. A aproximação com o MARE não apenas abriu novas perspectivas institucionais para o Inmetro, como também demonstrou a eficácia e adequação dos princípios da reforma. A transformação do Inmetro em Agência Executiva, juntamente com a formulação do correspondente Contrato de Gestão, a implantação de moderno sistema de planejamento estratégico e de gestão orçamentária constituem alguns dos aprimoramentos efetuados e que levaram, inclusive, o Instituto à conquista de prêmios e reconhecimentos formais junto ao Governo Federal. O sucesso do processo, porém, não se limitou a aspectos institucionais e formais, mas se refletiram tanto na sua imagem e desempenho, quanto na introjeção, entre seus integrantes, de valores fundamentais à moderna gestão, como o foco nos resultados e na satisfação do cliente, além da prática efetiva e ampla dos princípios da responsabilidade fiscal. Todavia, apesar do inegável êxito da mudança, o autor lança uma advertência quanto à necessidade da continuidade do processo de Reforma do Estado, especialmente no que toca às flexibilidades e autonomias administrativas, tão preconizadas na Reforma do Aparelho do Estado. Caso contrário, alerta o autor, dificilmente o Inmetro, ou qualquer outra instituição pública federal, poderá avançar mais no seu processo de modernização, correndo-se o risco de retrocessos nas conquistas já alcançadas.

\section{El proceso de modernización de Inmetro — informe de una experiencia Ricardo de Oliveira}

La intención del autor es mostrar que es posible avanzar en la implantación, en una institución pública brasileña, de modernos principios de gestión, mismo en un cuadro de fuertes restricciones. Ha sido justamente esta la trayectoria de Inmetro, que, desde inicios de la década de 90, desarrolla un vigoroso proceso de cambio. A partir de dado momento, Inmetro se aproximó del movimiento de Reforma del Aparato del Estado, guiado por $M A R E$, cuyas premisas mantenían una fuerte sintonía con los principios adoptados en la modernización del Instituto. La aproximación con MARE no solamente abrió nuevas perspectivas institucionales para Inmetro, como asimismo demostró la eficacia y adecuación de los principios de la reforma. La transformación de Inmetro en Agencia Ejecutiva, en conjunto con la formulación del correspondiente Contrato de Gestión, la implantación de moderno sistema de planificación estratégica y de gestión presupuestaria constituyen algunos de los perfeccionamientos efectuados y que llevaron, asimismo, al Instituto a la conquista de premios y reconocimientos formales junto al Gobierno Federal. El suceso del proceso, sin embargo, no se limitó a aspectos institucionales y formales, pero se han reflejados tanto en su imagen y desempeño, como en la introyección, entre sus integrantes, de valores fundamentales a la moderna gestión, como el enfoque en los resultados y en la satisfacción del cliente, además de la práctica efectiva y amplia de los principios de la responsabilidad fiscal. Asimismo, a pesar del innegable éxito del cambio, el autor lanza una advertencia con
Revista do

Serviço

Público

Ano 53

Número 4

Out-Dez 2002

Ricardo de

Oliveira é

engenheiro de produção pela UFRJ, exdiretor de operações e tecnologia da

Dataprev e atualmente é coordenador de planejamento do INMETRO, onde conduziu o processo de transformação do órgão em Agência

Executiva.

Contato: roliveira@ inmetro.gov.br 
relación a la necesidad de la continuidad del proceso de Reforma del Estado, especialmente en lo que se refiere a las flexibilidades y autonomías administrativas, tan preconizadas en la Reforma del Aparato del Estado. Caso contrario, alerta el autor, difícilmente Inmetro, o cualquier otra institución pública federal, podrá avanzar más en su proceso de modernización, corriendo el riesgo de retrocesos en las conquistas ya alcanzadas.

\section{Inmetro's modernization process - description of an experience}

\section{Ricardo de Oliveira}

The author's intention is to demonstrate that it is possible to implement modern management principles in a public Brazilian institution, even with a very restrictive organization. This exact trajectory has been the one adopted by Inmetro, who has developed a vigorous change process since the early 90's. At a certain point, Inmetro moved closer to the movement for State Organization Renovation conducted by MARE, whose assumptions had a strict relation with the principles adopted in the Institute's modernization. The proximity to MARE not only rendered new institutional perspectives to Inmetro, but also showed the efficiency and suitability of the renovation principles. The transformation of Inmetro into an Executive Agency, along with the formulation of the respective Management Agreement and the implementation of a modern system of budgeting and strategic planning, constitutes some of the accomplished improvements that also led the Institute to be formally awarded and recognized by the Federal Government. However, the success is not limited to institutional and formal aspects, but they are also reflected in its image and performance, with the introduction among its members of fundamental values of modern managing, such as the focus on results and client satisfaction-orientation, additionally to the effective and wide practice of tax responsibility principles. Nevertheless, in spite of the irrefutable success of the change, the author warns of the need to continue the State Renovation process, particularly regarding the administrative flexibilities and autonomies so emphatically proclaimed in the State Organization Renovation. Otherwise, the author alerts that Inmetro, or any other public federal institution, is not very likely to move further towards its modernization process, with the possibility to recede in current accomplishments. 
A Revista do Serviço Público é uma publicação da ENAP Escola Nacional de Administração Pública, voltada para a divulgação e debate de temas relacionados ao Estado, à administração pública e à gestão governamental. Procurando o aprimoramento permanente da revista, tanto no seu conteúdo quanto na apresentação gráfica, pedimos aos nossos colaboradores a observação das normas abaixo descritas.

\section{Normas para os colaboradores}

1. Os artigos, sempre inéditos no Brasil, devem conter em torno de 25 laudas de 20 linhas de 70 toques.

2. Os originais devem ser encaminhados ao editor, em arquivo digital, em programa de uso universal e enviados para editora@enap.gov.br . Usar apenas as formatações-padrão.

3. Cada artigo deve vir acompanhado de um resumo analítico em português, espanhol e inglês, de cerca de 150 palavras, que permita uma visão global e antecipada do assunto tratado.

4. Na primeira página do artigo, deve constar informação sobre formação e vinculação institucional do autor (em até duas linhas).

5. Notas, referências e bibliografia devem vir ao final do artigo, e não ao pé da página. Notas e referências, sendo o caso, devem vir devidamente numeradas.

6. Além de artigos, a revista receberá comunicações, notas informativas, notícias e relatórios conclusivos de pesquisas em desenvolvimento, com até 15 laudas. Resenhas de livros, em torno de 4 laudas, devem conter uma apresentação sucinta da obra e eventuais comentários que situem o leitor na discussão.

7. Os trabalhos que se adequarem à linha temática da revista serão apreciados pelo conselho editorial, que decidirá sobre a publicação com base em pareceres de consultores ad hoc.

8. Os originais enviados à Revista do Serviço Público não serão devolvidos. A revista compromete-se a informar os autores sobre a publicação ou não de seus trabalhos.

\section{Convite a resenhadores}

A Revista do Serviço Público convida todos os interessados em remeter resenhas de trabalhos publicados no Brasil e no exterior sobre Estado, administração pública e gestão governamental.

As resenhas devem ser originais e não exceder a cinco laudas datilografadas em espaço duplo com 20 linhas de 70 toques, e devem apresentar de modo sucinto a obra, com comentários que situem o leitor na discussão apresentada.

As resenhas devem ser enviadas em português, sem notas de rodapé, contendo o título completo e subtítulo do livro, nome completo do autor, local de publicação, editora e ano de publicação, bem como uma breve informação sobre a formação e vinculação institucional do resenhador (em até duas linhas), acompanhadas do respectivo disquete.

\section{Nota aos editores}

Pedimos encaminhar à Revista do Serviço Público exemplares de livros publicados, a fim de serem resenhados. Os resenhadores interessados receberão cópias dos livros enviados. 


\section{Solicitação de publicações}

Nome/Instituição:

CPF/CNPJ:

Endereço:

Cidade:

UF:

CEP:

Telefone:

Fax:

E-mail:

\section{Cartão de assinatura da RSP}

Periodicidade: trimestral

Assinatura anual: $\mathrm{R} \$ 40,00$

a Ano 53-2002

- Número avulso: $\mathrm{R} \$ 12,00$ Edição $n^{\circ}$

口 Exemplar avulso anterior a 1997: $\mathrm{R} \$ 8,00$

\section{Cadernos ENAP}

$\begin{array}{lllllllll}\square 4 & \square 5 & \square 6 & \square 7 & \square 8 & \square 9 & \square 10 & \square 11 & \square 12\end{array}$

$\begin{array}{llllllll}\square 13 & \square 14 & \square 15 & \square & \square & \square & \square & \square\end{array}$

Preço unitário: $R \$ 10,00$

Texto para discussão

\begin{tabular}{llllllllll}
\hline 1 & $\square 2$ & $\square 3$ & $\square 4$ & $\square 5$ & $\square 6$ & $\square 7$ & $\square 8$ & $\square 9$ & $\square 10$
\end{tabular}

$\begin{array}{llllllllll}\square 11 & \square 12 & \square 13 & \square 14 & \square 15 & \square 16 & \square 17 & \square 18 & \square 19 & \square 20\end{array}$

$\begin{array}{llllllllll}\square 21 & \square 22 & \square 23 & \square 24 & \square 25 & \square 26 & \square 27 & \square 28 & \square 29 & \square 30\end{array}$

$\begin{array}{llllllllll}\square 31 & \square 32 & \square 33 & \square 34 & \square 35 & \square 36 & \square 37 & \square 38 & \square 39 & \square 40\end{array}$

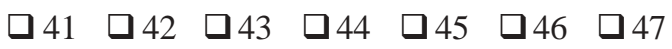

Números 1 ao 5: $R \$ 3,00$

A partir do número 6: $R \$ 5,00$

Forma de pagamento ver orientação no verso

$\square$ Cheque nominal $\square$ Ordem de pagamento $\square$ Nota de empenho 


\section{Forma de pagamento}

- Cheque nominal à ENAP Fundação Escola Nacional de Administração Pública.

- Ordem de pagamento (anexar cópia do comprovante de depósito) em nome da ENAP Escola Nacional de Administração Pública, através do Banco do Brasil S/A, Agência Ministério da Fazenda 3602-1, Conta Corrente: 170500-8 Depósito identificado (código - dv) finalidade: 11470211401002-2.

- Nota de empenho em nome da ENAP Escola Nacional de Administração Pública (anexar original). (UG:114702, Gestão: 11401).

ENAP Escola Nacional de Administração Pública Diretoria de Informação e Conhecimento em Gestão SAIS - Área 2-A 70610-900 — Brasília, DF Tel: (61) $4457096 / 4457102$ —Fax: (61) 4457178 CNPJ: 00627 612/0001-09

Site: www.enap.gov.br

E-mail: publicacoes@enap.gov.br 